\title{
BITKA I POETIKA
}

\author{
Milun Lutovac \\ Univerzitet Donja Gorica, Fakultet umjetnosti, \\ Podgorica
}

va istorijska događaja: bitka između Kraljevine Crne Gore i AustroUgarske monarhije, početkom januara 1916. godine, i potom, austrijska okupacija Crne Gore (1916-1918), inspirativno su izvorište i tematska preokupacija romana „Nevidbog“ (1933) Rista Ratkovića; „Dukljanska zemlja“ (1939) Dušana Đurovića; „Crna Gora“ (1958) Milovana Đilasa; „Ratna sreća“ (1973) Mihaila Lalića; „Mojkovačka bitka“ (1968) Ćamila Sijarića; „Pod Skadrom“ (1979) Čeda Vukovića i „Razvršje“ Mila Boškovića (nedovršen roman).

Pored iste građe i tematike, romane mojkovačkog književnog kruga povezuje intenzivno prisustvo psihoze neizvjesnosti i straha koje, na tipično crnogorski način, naporedo egzistiraju sa odlučnošću naroda na otpor agresoru, bez obzira na cijenu. Zbog prožimanja njihovih elementa i struktura, recipijent in doživljava kao jednu romanesknu cjelinu, nastajalu tokom trideset pet godina. Ne samo zbog korišćenja iste građe, već i zbog intertekstualnosti narativnih struktura i elemenata, ovi romani čine jedan narativni ciklus za koji se čini prikladno određenje - mojkovački književni krug.

Ključne reči: Risto Ratković, Dušan Đurović, Milovan Đilas, Ćamil Sijarić, Crna Gora, Mojkovačka bitka, mojkovački književni krug, intertekstualnost

\section{Intertekstualnost romana mojkovačkog književnog kruga ${ }^{1}$}

Savremena teorijska misao termin „književno djelo“ sve češće zamjenjuje pojmom


tekstualnost je determinisana na različite načine. U širem smislu označava zavisnost tekstova jednih o drugima, a u užem smislu označava odnos među književnim tekstovima od kojih je za razumijevanje jednog potrebno poznavanje drugog teksta. Novo značenje intertekstualnosti dali su poststrukturalisti stavovima „da se značenje jednog djela jedino može tumačiti odnosom s drugim djelima“2.

\footnotetext{
${ }^{1}$ Insert iz doktorske disertacije M. Lutovca „Modernistički narativni modeli u romanima "Crna Gora” Milovana Đilasa i "Mojkovačka bitka" Ćamila Sijarića.

${ }^{2}$ Solar, Milivoj, Književni leksikon, Matica Hrvatska, Zagreb, 2007, 164
} 
U ovom radu i u vezi s romanima mojkovačkog književnog kruga intertekstualnost se sagledava kroz dvije dimenzije: kao uticaj jednih tekstova na druge, u manjoj mjeri, i kao prisustvo tragova drugih tekstova, u većoj mjeri. Pod tragovima ili odrazima drugih tekstova podrazumijevaju se metatekstualna značenja, reminescencije, kodovi tradicije, dijalozi, atmosfera i psihoza bitke. Teoretičarka Julija Kristeva (kojoj se pripisuje termin intertekstualnost) tekst je opisala kao permutaciju tekstova, preuzetih iz drugih tekstova, koji se međusobno ukrštaju i jedni druge neutralizuju. ${ }^{3}$

Žerar Ženet je smatrao da intertekstalnost predstavlja odnos koji književni tekst uspostavlja s društvenim tekstom pomoću naslova, predgovora, ilustracija... U vezi s intertekstualnošću, Ženet je sugerisao niz inovacija i distinkcija tog pojma. Međutim, pitanje odnosa između raznih djela i raznih tekstova je stalno aktuelno. I pored dosadašnjih istraživanja i otkrića, još nije objašnjeno mnogo fenomena intertekstualnosti, kao, na primjer, "neposredni i namjerni citati", kombinovanje tuđih tekstova, korišćenje kolaža itd.

Možda će ovaj, sažeti, pregled teorijskih stavova o intertekstualnosti pomoći njenom sagledavanju u romanima mojkovačkog književnog kruga.

Intertekstualnost ovih romana satkana je od široke i složene mreže srodnih i analognih struktura, elemenata, modela, narativnih tokova i to, od prologa, do tragičnih epiloga romana. Bitni elementi intertekstualne strukture su događaji: bitka i okupacija; temporalno-prostorne koordinate; kontekst tradicije; tragične sudbine junaka romanâ, te prikaz vojske, naroda i zemlje u „tamnom vilajetu“ Velikog rata. Intertekstualnost ovih djela odražava se i na unutrašnjem narativnom planu - korišćenjem modernističkih tehnika i modela naracije: lajtmotiva, simultanosti, unutrašnjeg monologa, ili promocijom aktuelnih poetika određenog vremena, kao u romanima „Nevidbog“4 - avangarda, i „Dukljanska zemlja"s - socijalna literatura.

Pored tematike, romane intertekstualno povezuju i motivi o bici, o zimskim pejzažima, o psihologiji likova, o starcima i ženama - učesnicima rata, o tragici bitke i veličini otpora. Predstavnici stare garde su Vuk od Rovaca, roman „Crna Gora"6 i Vidak Kuč, roman „Mojkovačka bitka", plastično izvajani i vrednovani s pozitivne tačke gledišta. Izmorene povorke žena, njihovi ispaćeni likovi, ali i njihova odlučnost, stoicizam, hrabrost i, iznad svega, visoki moral, originalno su i kreativno prikazani u narativnim cjelinama predmetnih romana. Od mnogo primjera njihovog morala i shvatanja, navodimo samo dva: majka moli sina jedinca koji je pobjegao iz bitke da se „vrati u družinu“, i kad on to ne prihvata, proklinje ga („Mojkovačka bitka“). Sestri su u bici poginula dva brata - barjaktara i ona traži od trećeg brata, koji se uplašio, da prihvati barjak ili će to ona učiniti. I uspijeva u svojoj namjeri. („Crna Gora“).

Intretekstualnost između romana izrazita je i u prikazu i djelovanju dva bataljona koje predvode poručnik Petar Žurić („Crna Gora“) i komandir Radič Memić („Mojkovačka bitka“). Ipak, ona je najizrazitija u epiloškim narativnim cjelinama. Glavni likovi ginu ili umiru jedan za drugim. Nad poprištem bitke odliježu lelek i tužbalica, žene traže svoje najbliže

\footnotetext{
${ }^{3}$ Prema: Rebronja, Nadija, Romani Ćamila Sijarića između tradicionalnog i modernog, Novi Sad, 2013, 17.

${ }^{4}$ Ratković, Risto, Nevidbog, Daily Press, Podgorica, 2006.

${ }^{5}$ Đurović, Dušan, Dukljanska zemlja, Zmaj-Pegaz, Bijelo Polje, 2005.

${ }^{6}$ Đilas, Milovan, Crna Gora, Obod, Cetinje, 1994.

${ }^{7}$ Sijarić, Ćamil, Mojkovačka bitka, Veselin Masleša, Sarajevo, 1981.
} 
- ranjene i mrtve, pokazujući snagu i dostojanstvo koji prevazilaze antičke uzore. U toj pokori i nesreći, akteri bitke, teže od same smrti, doživjeli su naredbu o raspuštanju vojske i predaji oružja u bici koju nijesu izgubili.

M. Đilas piše da Mojkovačka bitka nije imala pobjednika, dok je Sijarić u opisu ishoda bitke subjektivniji i pridaje mu prizvuk pobjede.

Potpuno demoralisan, komandir Radič nalazi snage da obodri vojnike:

„I mogu vam reći toliko: da je vaša puška bila jedina koja je danas na Balkanu pucala... oni što će u goru, a neće kućama, nek ponesu oružje da se bore i dalje, ali kao narod; i ja ću tamo." (Sijarić: 331).

Komparativna analiza romana „Nevidbog“ i „Dukljanska zemlja“ ukazuje, takođe, na paralelizam u njihovom prikazu „slike svijeta“, kao i na intertekstualnu srodnost i povezanost narativnih struktura i elemenata. Najviše ih povezuje centralna tema - austrijska okupacija u uzročno-posljedičnoj vezi sa bitkom.

Samoj bici, njenom kontroverznom ishodu, psihozi koju je izazvala u narodu i njenim tragičnim posljedicama, dat je značajan prostor u oba romana. Zanimljivo je da teme i motivi ovih romana, iz četrdesetih godina XX vijeka, korespondiraju i intertekstualno se povezuju sa romanom „Mojkovačka bitka“ Ć. Sijarića iz 1968. godine. Između ova tri romana neznatne su razlike u prikazu zbivanja u pozadini, dobrovoljačke vojske, žena učesnica i žrtava rata, tragičnih ljubavi: Umka - Radič („Mojkovačka bitka“); Đorđe - Vasvija („Nevidbog“); Branko - Mirjana („Dukljanska zemlja“) a, naročito, u atmosferi beznađa, raspada patrijarhalne porodice i tragici likova i naroda.

Primjera za intertekstualnost romana mojkovačkog književnog kruga je na pretek, zbog čega je ilustrujemo samo karakterističnim i tipičnim izvodima. Najveće prepreke Umkinoj i Radičevoj ljubavi bile su predrasude njene porodice, koja nije mogla ni da shvati, ni da prihvati, da se ona uda za čovjeka druge, tuđe, vjere („Mojkovačka bitka“), i ratni haos. Zanos ljubavi Đorđe je platio životom, a Vasvija ludilom („Nevidbog“). Bili su žrtve vjerskog kanona. Zanimljiv je detalj da je u oba romana mržnja prevaziđena - Umkin brat Šućro oprostio je Radiču, a Obrad - Đorđijevom ubici. To su bili prvi nagovještaji promjena na licu vjekovne dogme.

Intertekstualna umreženost ovih romana naročito je izražena u prikazu austrijske okupacije: psihoza straha i neizvjesnosti, interniranje uglednih ličnosti, rekvizicija svega što narod ima - do crkvenih zvona, svakodnevna nasilja i vješanja, uz epidemiju „španjolice“, koja je prepolovila stanovništvo. U intertekstualni krug vremena austrijske okupacije spada i dio iz romana „Crna Gora“ - „Vješala“, mada je drugačije koncipiran i usmjeren na svijest likova osuđenih na smrt, dan pred pogubljenje. Intertekstualni paralelizam izrazito se ogleda u prikazu glavnih likova, njihovih sudbina i propasti njihovih porodica: trgovca Obrada Jeremića („Nevidbog“); patrijarhalnog domaćina Gorčina Knežića („Dukljanska zemlja“) i islamskog prvaka Redžepa Karadašića („Mojkovačka bitka“). Narativni scenario o njima razlikuje se u nijansama, a istovjetne su im sudbine, stradanje čitavih porodica i njihovo ekonomsko propadanje, kao posljedica surove okupacije, ali i nepokornosti i etičnosti ovih likova.

U romanima postoji identičnost i u opisu dobrovoljačke vojske.

„Sve sam pešak. U seljačkom odelu, neki opremljeni malo bolje, no mnogi i mnogi onako kako su se zatekli na njivi sa polovnim ili pocepanim opancima. Iđahu većinom pognuti i zamišljeni, no čim bi nastupili kroz varoš, dizahu glave i pesma im se vijaše, zajedno sa barjakom." (Ratković: 56$)$. 
Iskustva i pouke iz prošlosti

„A takvi su i bili - kao kosci koji su došli da kose na mobu, jer su bili vojska dobrovoljačka, trubama na vojnu nepozvana, u spiskove neupisana, na vjernost nikome ne zakleta i u crkvama nepričešćena." (Sijarić: 56).

Na sličan način vojsku prikazuje i M. Đilas:

„Ali ne ratuje samo vojska. Ni muški jedino. Ratuje sva Crna Gora - Crnogorke." (Đilas: 7).

U romanu „Dukljanska zemlja“ prikazan je niz motiva o ratištu, konkretno hercegovačkom, gdje je vojska odstupila bez borbe, što su vojnici doživjeli kao izdaju. Međutim, fragmenti tog ratišta, na kome se i nije desila bitka, dio su šireg konteksta sukoba dvije države i, jedan od oblika otpora, koji je kulminirao u Mojkovačkoj bici. Ona se u ovom romanu eksplicitno slavi i neka je vrsta sinteze svih romana ovog kruga.

„To je poslednja i najslavnija bitka crnogorska... Ljudi nisu mislili ni na oca ni na ženu, ni na đecu. Bila je jedna jedina misao: pobijediti, i pasti za slobodu svoga kamena..." (Đurović, 162)

Tradicionalne predstave, pod kojima podrazumijevamo fenomene mitskog, arhetipskog, folklornog..., jedan su od najživljih protoka intertekstualnosti odabranih romana. One su odraz civilizacijskih i vjerskih uticaja, kao i identitetsko - mentalitetskih struktura. Ilustrujemo ih samo sa nekoliko primjera:

„Bio je iznemogao. Znojio se, kupio u klupče, tražio vode i šaputao kako mu nedostaje vazduha... Biće stao na sugreb!- šaputala je Fima. Jutros je bio zdrav. Sugreb... sugreb... sugreb..." (Đurović: 240-241).

Košmari, halucinacije i snovi su čest motiv u ovim romanima. U snove se vjeruje kao u javu. Čak i više. Gorčin sanja oca koji ga kori zbog izgubljene njive.

„Za njom kukaju naše duše. Nemirni smo. Nas nešto progoni i muči i već čujemo u našim grobovima glas potomstva koji strašno proklinje... Ne daj, Gorčine, ne daj našu divnu Londžu..." (Đurović: 100).

Kult predaka, po čemu se Crnogorci i Hercegovci razlikuju od ostalih balkanskih naroda (J. Cvijić), naglašen je u svim romanima mojkovačkog književnog kruga, a naročito u romanu „Crna Gora“.

„Iz zaboravljenih grobova ustaju skeleti praotaca i rodonačelnika i idu od kuće do kuće na svaka vrata i proklinju da njihove muke i njihove kosti ne ostanu nepokajane." (Đilas: 6).

U Sijarićevom romanu „Mojkovačka bitka“ prikazan je širok spektar tradicionalnih predstava, a među njima dominiraju - vjerovanje u predodređenost, sudbinu:

„Udaljavamo se, Redžepe, otkad smo živi.

Bog ljude sastavlja i rastavlja... neka tako i ostane.

Ama ponešto čine i ljudi.

Koliko im to sudbina dopusti...", veli Redžep Maksimu Tucanji.

„On je (Redžep Karadašić n.n) naučio da se o bogu i sudbini govori samo meko... I to što su sada u tim jaslama, volja je sudbine. I ako ih sjutra pomore, i to će biti po božjoj volji. (Sijarić: 185).

Roman „Nevidbog“ u intertekstualnom pogledu nalazi se između „Dukljanske zemlje“ i „Mojkovačke bitke“. Sa romanom Dušana Đurovića povezuju ga motivi okupacije, naročito straha, gladi, epidemije španjolice i propadanja patrijarhalnog načina života. Sa Sijarićevim romanom povezuju ga drugačije intertekstualne scene: tradicionalna vjerska podvojenost i mržnja, liričnost, kao i model poetizacije pripovjedanja, i metaforičnost. llustrujemo ih jednim primjerom, nevjerovatne podudarnosti. 
Prepredenost „božijeg sluge“ i zelenaša Haliodže u „Nevidbogu“ izražena je epitetskim lajtmotivom:

„Žuta čalma, žute oči, žuti zubi. Žut osmeh..."(Ratković: 85).

Intertekstualnost romana mojkovačkog kruga proizvod je korišćenja građe o istim istorijskim događajima, o brzim promjenama u drugoj deceniji prošlog vijeka, o stvarnom i psihološko - emocionalnom prostoru Sandžaka, Polimlja, Gornjeg Potarja, te o tragici, kako naroda u cijelini, tako i individua. Svi ti fenomeni, u manjoj ili većoj mjeri, dio su struktura i narativnih tokova ovih romana. Intertekstualno su intenzivnije povezani romani „Nevidbog“ i „Mojkovačka bitka“. U vezi s tim nameće se prva misao da je to logično, jer im je narativno izvorište Sandžak, njegova bipolarnost i egzotičnost, ali pažljivija komparacija ova dva romana navodi na sud o nesumnjivom uticaju R. Ratkovića na C. Sijarića, naročito u pogledu izrazite liričnosti teksta, te upotrebe izraza i korišćenja figura.

Na kraju ovog osvrta za intertekstualnost romana mojkovačkog književnog kruga treba istaći i njihovu metatekstualnu povezanost sa djelima crnogorske tradicije, naročito u segmentima i narativnim cjelinama etičke prirode. Najviše su, nešto modifikovane, korišćenje misli iz „Gorskog vijenca“:

„Udar je i njegovu varnicu iskresao." (Đilas: 20)

/Udar nađe iskru u kamenu“ - P. P. Njegoš/.

Metatekst Vidaka Kuča, viteza iz brojnih crnogorskih ratova, je kosovski mit i junačka narodna pjesma:

„Ovo je crnina na ovoj kapi (crnogorskoj, n.n) za Kosovom; od Kosova ovamo sve je crno, a nije crno samo ovo polje koje predstavlja Crnu Goru - zato što je, đetiću, Crna Gora slobodna."(Sijarić: 49).

Metatekstualnost romana mojkovačkog književnog kruga najčešće se javlja u vezi sa čovjekovom sudbinom, misijom i odgovornošću pred sobom i narodom u varijacijama Njegoševe sentence: „Što je čovjek, a mora bit čovjek!“ Slične su metatekstualne refleksije o životu. Drugačije ga, jedino, u duhu avangardne poetike, predstavlja R. Ratković.

„Život je topla krv. Život je ptica. Život je ptica bez krila. Život su krila bez ptice. Život je ptica sa krilima. Život je ptica što zapaljena leti u noći. Život je mala zabuna. Život je aleluja, oputo. Život je zbogom." (Ratković: 155).

Originalan, pjesnički doživljaj života munjevitog leta, od „tople krvi“ do „aleluja“ i „zbogom".

Poznat je fenomen saživljenosti stvaralaca sa zavičajem ili određenom sredinom koju su fikcionalno otkrili i predstavili svijetu, proslavivši se međusobno: Servantes, Tven, Fokner, Džojs, Šolohov, Andrić... Mnogo je rjeđa pojava da jedna sredina ili događaj kreativno podstaknu više stvaralaca, kao što su, u ovom kontekstu, Sandžak i Mojkovačka bitka. To je nesumnjiv znak egzotičnosti miljea, još više istorijskog značaja događaja i njegovog uticaja na sudbinu Crne Gore. Međutim, susret i ukrštanje egzotičnih motiva gluve provincije s dramatičnošću i tragičnošću posljednje bitke stare države za slobodu, bili su inspirativna građa za kreativno prikazivanje opšteljudskih egzistencijalnih problema u djelima autora ovog književnog kruga.

$\mathrm{Na}$ osnovu ove analize zaključujemo da romani mojkovačkog književnog kruga u periodici crnogorske romaneskne proze čine poseban socijalno-psihološki, fikcionalni i poetički ciklus. 


\section{Literatura}

[1] Andrić Ivo: Prokleta avlija, Oktoih, Podgorica, 2007.

[2] Bahtin Mihail: O romanu, Nolit, Beograd, 1989.

[3] Bal Mike: Naratologija - teorija priče i pripovedanja, Narodna knjiga - Alfa, Beograd, 2000.

[4] Bart Rolan: Književnost mitologija semiologija, Nolit, Beograd, 1979.

[5] Bečanović Tatjana: Poetika Lalićeve trilogije, CANU, Podgorica, 2006.

[6] Beker Miroslav: Tekstualnost, u: Intertekstualnost i intermedijalnost, Zavod za znanost o književnosti, Zagreb, 1988.

[7] Miroslav Beker: Suvremene književne teorije, Liber, Zagreb, 1986.

[8] Đilas Milovan: Crna Gora, Obod, Cetinje, 1994.

[9] Đurović Dušan: Dukljanska zemlja, Zmaj-Pegaz, Bijelo Polje, 2005.

[10] Ivanović Radomir: Poetika Rista Ratkovića, Univerzitetska riječ, Nikšić, 1990.

[11] Kafka Franc: Proces, Daily Press, Podgorica, 2003.

[12] Kami Alber: Stranac, Daily Press, Podgorica, 2003.

[13] Kayser Wolfang: Nastanak i kriza modernog romana, Nolit, Beograd 1979.

[14] Kenan Š. R., Narativna proza, Narodna knjiga - Alfa, Beograd, 2007.

[15] Konstantinović Zoran: Fenomenološki pristup književnom delu, Beograd, 1969.

[16] Lalić Mihailo: Lelejska gora, Nolit, Beograd, 1965.

[17] Lešić Zdenko: Književni tekst u mreži intertekstualnosti, u: Nova čitanja, Poststrukturalistička čitanka, Buybook, Sarajevo, 2003.

[18] Lotman M. Jurij: Struktura umetničkog teksta, Nolit, Beograd, 1985.

[19] Lukač Đerđ: Teorija romana, Izdavač, Beograd, 1990.

[20] Mandeljštam Osip: Kraj romana, Roman, Nolit, Beograd, 1975.

[21] Marčetić Adrijana: Figure pripovedanja, Narodna knjiga - Alfa, Beograd, 2003.

[22] Peleš Gajo: Tumačenje romana, Artesor naklada, Zagreb, 1999.

[23] Petrović Petar II Njegoš, Gorski vijenac, Celokupna dela Petra II Petrovića Njegoša, Prosveta, Beograd, 1974.

[24] Ratković Risto, Izabrana djela, knj. IV, Nikšić, 1991.

[25] Ratković Risto, Nevidbog, Daily Press, Podgorica, 2006.

[26] Riker Pol : Vreme i priča, IK Zoran Stojanović, Beograd, 1993.

[27] Rebronja, Nadija, Romani Ćamila Sijarića između tradicionalnog i modernog, Novi Sad, 2013.

[28] Sijarić Ćamil, Bihorci, Veselin Masleša, Sarajevo, 1981.

[29] Sijarić Ćamil, Mojkovačka bitka, Veselin Masleša, Sarajevo, 1981.

[30] Sijarić Ćamil, Zelen prsten na vodi, Veselin Masleša, Sarajevo, 1981.

[31] Solar Milivoj: Teorija književnosti i rječnik književnoga nazivlja, Glasnik, Beograd, 2012.

[32] Solar, Milivoj, Književni leksikon, Matica Hrvatska, Zagreb, 2007.

[33] Solar Milivoj: Ideja i priča, Liber, Zagreb, 1974.

[34] Štancl Franc: Tipične forme romana, KZ, Novi Sad, 1987.

[35] Tomaševski Boris, Teorija književnosti / Tematika, Zagreb, 1998.

[36] Uspenski A. Boris: Poetika kompozicije; Semiotika ikone, Nolit, Beograd, 1979.

[37] Velek Rene - Voren Ostin: Teorija književnosti, Nolit, Beograd, 1985.

[38] Ženet Žerar: Figure, Svetovi, Novi Sad, 2002. 